\title{
Catching-up Countries - Lessons for Bulgaria
}

\author{
Assoc. Prof. PhD Hristo Mavrov \\ University of Economics - Varna, Varna, Bulgaria \\ mavrov_h@ue-varna.bg
}

\begin{abstract}
The data show that nowadays Bulgaria is lagging far behind in its development than other countries in the European Union. That is why catching up with developed countries is a key task for bulgarian economy. The article explores the causes that accelerate economic growth. For this purpose, five countries with the highest average annual GDP per capita growth rates for the period 1870-2016 are identified. Data used comes from the Maddison Project Database. By selecting and analyzing theoretical and empirical literature examining the success of these five countries, it is concluded that catching up is possible, but a unique, economic model is needed. At the same time, those factors, without which rapid development is impossible are determined.
\end{abstract}

Keywords: economic growth, catching-up countries, Maddison database, real GDP per capita, Bulgaria, East Asia

JEL Code:A00; doi:10.36997/IJUSV-ESS/2019.8.2.180

\section{Въведение}

Няколко основни факта характеризират равнището и динамиката на икономическото развитие на България през последните години и представляват сериозно предизвикателство както за икономистите-изследователи, така и за осьществяващите икономическата политика на страната. От една страна по размер на БВП на човек от населението България изостава значително от европейските страни. Нещо повече - по данни на Евростат България е на последно място в Европейския съюз (ЕС): ако БВП на човек в ЕС се приеме за сто, то за България този показател през 2018 г. е точно половината - 50,2\%. Последните две страни преди България - Румъния и Хърватия имат съответно БВП на човек е равен на 64,6\% и $62,9 \%$ от средния за ЕС - значително над този на нашата страна (виж фиг. 1$)^{1}$.

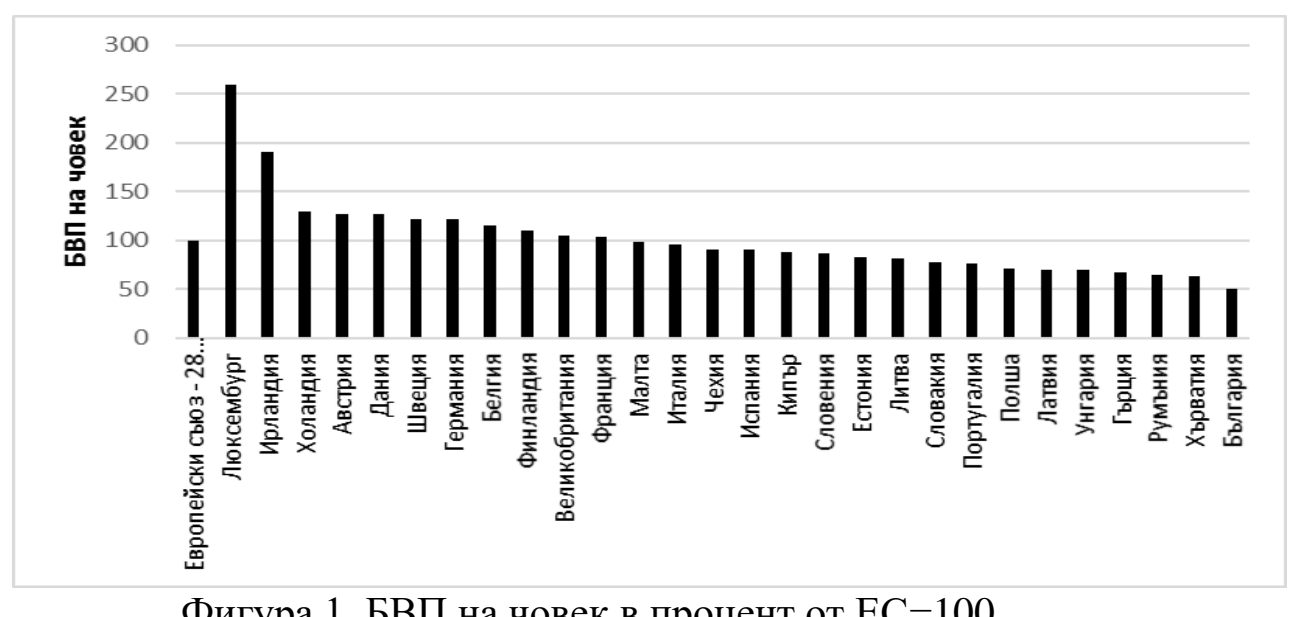

Равнището на БВП на човек за България в сравнение с другите страни е обезпокоително, но по-обезсърчителна е неговата динамика през последните години. Тя е значително по-слаба от тази на нашата съседка, Румъния - за периода от 2007 г. до 2018 г. увеличението в България е едва 10 процентни пункта, докато за Румъния то е два пъти повече - от 43\% на 64\% - т.е. 21 процентни пункта. България изостава не само от Румъния.

\footnotetext{
${ }^{1}$ Eurostat, https://ec.europa.eu/eurostat/databrowser/view/tec00114/default/table?lang=en
} 
Сравнението на темповете на нарастване на реалния БВП на България с другите европейски страни показва, че почти всички страни от Източна Европа (с изключение на Словения и новоприетата в ЕС Хърватия) имат по-голяма динамика (виж. фиг.2).

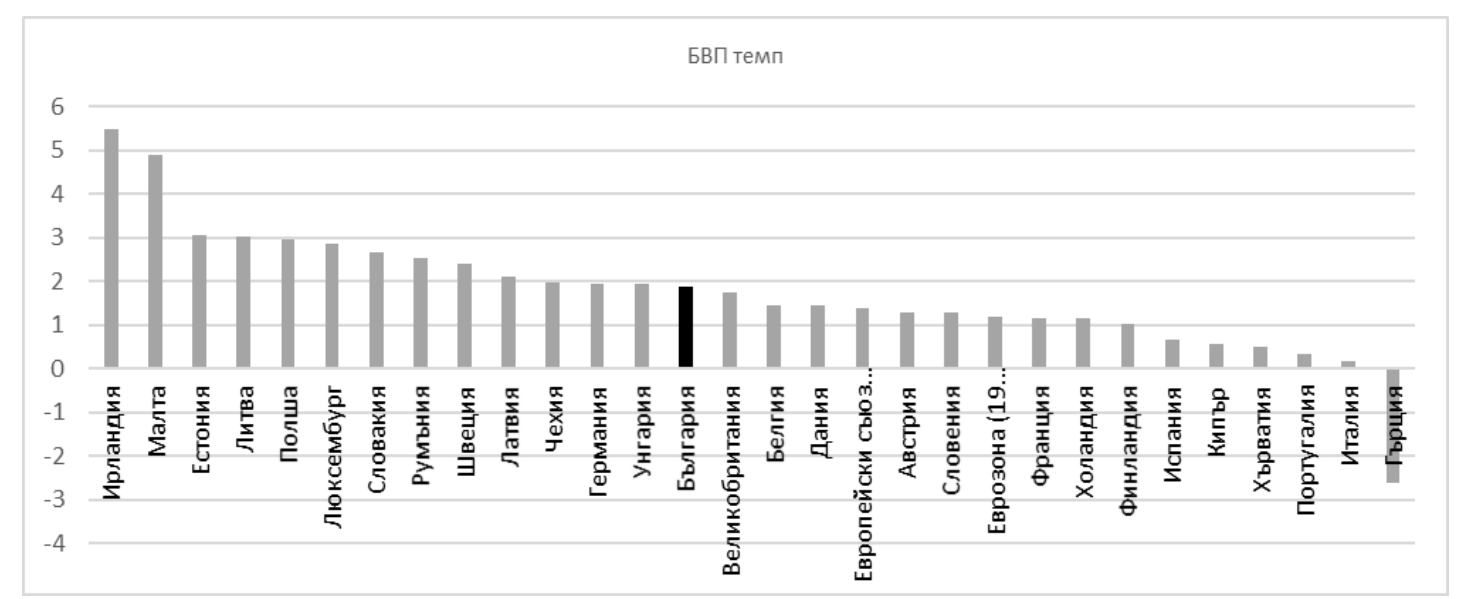

Фигура 2. Средногодишен темп на растеж на реалния БВП в ЕС-28 за периода 2010-2019

България е по средата на направената класация, на 14 място от 28-те страни на ЕС, със средногодишен темп на растеж от $1,88 \%$. Очевидно е, че с подобна скорост на развитие не би могло да се осъществи догонване. Трябва да се открои и впечатляващият растеж на Ирландия и Малта през периода след кризата от 2008 г.- съответно 5,4\% и 4,9\%.

Безспорно, най-важната задача на нашата страна е догонване на напредналите страни, или поне значително намаляване на разрива ни с тях във възможно по-кратки срокове. Това от своя страна означава ускоряване на икономическия растеж. Какви са предпоставките за подобен растеж ще потьрсим в практиката на страните, осъществили икономически прелом в следвоенните години.

Така поставеният научно-изследователски въпрос насочва основната цел на тази статия към идентифициране на онези страни в икономическата история, осъществили в рамките на едно поколение (30-40 години) догонване на развитите страни и открояване на онези общи фактори, без които подобна динамика е невъзможна.

В структурно отношение проведеното изследване възприема следната логика: първо, установяване на страни в икономическата история и преди всичко съвременната, които са осъществили икономически скок, догонване, и от сравнително изостанали са се превърнали в развити страни; второ, преглед на литературата и обобщаване на основните фактори, довели до ускореното развитие на тези страни, и трето, извеждане на поуки за възможното ускорено развитие на България.

\section{1. Най-динамичните в дългосрочен план страни}

Процесът на изследване включва следните няколко стъпки: на първо място селектиране на определен брой страни, които са реализирали най-високи темпове на растеж на БВП на човек за последните 150 години; на второ място, определяне на периода (периодите) на най-динамично развитие за всяка една страна.

Използваните исторически данни за БВП са от динамичните серии на А. Мадисън ${ }^{2}$. Периодът на изследване за темповете на растеж на реалния БВП на човек от населението е от 1870 г. до 2016 г. Този период е разделен на два подпериода - 1950-1980 г. и 1980-2016 г. Целта е да се обхванат всички страни осъществили догонване на основата на дългосрочно по-високи темпове на растеж макар и в различно историческо време.

\footnotetext{
${ }^{2}$ Maddison Project Database, version 2018.
} 
Първата стъпка в анализа е открояването на страните с най-динамично развитие за периода 1870-2016 г. и сравнението им с най-богатите страни през 1870 г. които остават такива и в днешни времена. В статистиката на А. Мадисън за възприетата от нас начална година 1870 отсъстват данни за повече от 100 страни. Така в групата на оценяваните страни попадат 66 икономики. Изчисляването на средногодишния темп на растеж на реалния БВП на глава от населението и подреждането на страните води до резултати за петте страни с найвисоки темпове на нарастване, показани в табл.1.

Таблица 1. Страни с най-висок темп на растеж за периода 1870-2016 г.

\begin{tabular}{|c|l|c|c|c|}
\hline ранк & Страна & $\begin{array}{c}\text { БВП на } \\
\text { човек през } \\
\mathbf{1 8 7 0} \text { г. }\end{array}$ & $\begin{array}{c}\text { БВП на } \\
\text { човек } \\
\text { през 2016 г. }\end{array}$ & $\begin{array}{c}\text { Средногодишен } \\
\text { темп на растеж } \\
\text { на БВП на } \\
\text { човек }\end{array}$ \\
\hline 1 & $\begin{array}{l}\text { Република } \\
\text { Корея }\end{array}$ & 465 & 36103 & 3,02 \\
\hline 2 & Тайван & 897 & 42165 & 2,67 \\
\hline 3 & Хонг Конг & 1067 & 48330 & 2,65 \\
\hline 4 & Сингапур & 1794 & 65729 & 2,50 \\
\hline 5 & Япония & 1160 & 37465 & 2,41 \\
\hline
\end{tabular}

Източник: Изчисленията са на автора по данни от Maddison Project Database

С най-висок средногодишен темп на растеж на БВП на човек за този 159 г. период се оказва Корея с темп от 3,02\%. Следващите места се заемат също от страни от Източна Азия Тайван, Хонг Конг, Сингапур и петицата завършва с Япония.

Очевиден е ефектьт на темп на растеж с 1 процентен пункт по-висок от този на други страни за период от 150 години. Великобритания, която е най-богатата страна в света през 1870 г. (втора след Австралия по БВП на човек) е имала БВП на човек почти пет пъти повисок от този на Япония (виж табл. 1 и табл. 2). В резултат на по-високия с 1,1 процентни пункта темп през 2016 г. Япония вече е на нивото на Великобритания ${ }^{3}$. Безспорно найзначим е скокът на Република Корея, която през 1870 г. е от една от най-бедните страни с БВП на човек 12 пъти по-малък от този на Великобритания, а през 2016 г. вече е сравнима с нея. Причината е, че темпът на нарастване на Р.Корея е 1,73 процентни пункта по-висок от този на Великобритания. Огромен е и прогресът на Сингапур, чието изоставане от Великобритания е около 3 пъти през 1870 г., а в края на периода има БВП на човек 1,76 пъти над този на Великобритания. Темпът на растеж на Сингапур е 1,21 процентни пункта над този на бившата си господарка - Великобритания ${ }^{4}$ (виж табл.1 и табл.2).

Посочените в табл.1 темпове на растеж са средногодишни за целия 150 г. период. Това естествено не означава, че изчислените темпове са едни и същи за всяка година на изследвания период. Тези темпове са средни - т.е има периоди, в които темповете са значително над средните, както и периоди, в които те са под средните. Нас ни интересуват

\footnotetext{
${ }^{3}$ Всъщност Япония настига Великобритания още през 1979 г. когато БВП на човек за двете страни почти се изравняват и са съответно 20714 и 20580. През следващите години високите темпове на Япония рязко спадат и тя изпада в стагнация в продължение на повече от 20 години.

${ }^{4}$ Сингапур е британска колония от 1867 г. до 1959 г. Истинската независимост е постигната през 1965 г., когато Сингапур напуска Малайската федерация (член на която доброволно е от 1962 г.), но основите на ускореното развитие се поставят още през 1959 г., в рамките на статута си на кралска колония със самостоятелно управление се провеждат избори, спечелени от Ли Куан Ю. Той именно е стратегът на превръщането на Сингапур от изостанала в свръх развита страна. През 2016 г. със своите 65729 долара на човек Сингапур, беден на ресурси островен град-държава, е на 5-то място в света след богатите на петролни ресурси държави като Катар, Норвегия, ОАЕ и Кувейт. Класация на автора по данни от Maddison Project Database, version 2018.
} 
онези периоди, в които тези страни са се развивали особено динамично и поради това са допринесли за високия дългосрочен темп на растеж.

Таблица 2. Ранк и темпове на растеж на най-богатите през 1870 г. страни

\begin{tabular}{|l|l|l|l|c|c|c|c|}
\hline \multirow{2}{*}{ № } & & \multicolumn{4}{|l|}{$\begin{array}{l}\text { Реален БВП } \\
\text { на човек }\end{array}$} & \multicolumn{4}{l|}{$\begin{array}{l}\text { Средногодишен темп на нарастване } \\
\text { на реалия БВП на човек }\end{array}$} \\
\hline & Страни & $\mathbf{1 8 7 0}$ & $\mathbf{2 0 1 6}$ & $\begin{array}{l}\mathbf{1 8 7 0}- \\
\mathbf{2 0 1 6}\end{array}$ & $\begin{array}{l}\mathbf{1 9 5 0 -} \\
\mathbf{2 0 1 6}\end{array}$ & $\begin{array}{l}\mathbf{1 9 5 0 -} \\
\mathbf{1 9 8 0}\end{array}$ & $\begin{array}{l}\mathbf{1 9 8 0}- \\
\mathbf{2 0 1 6}\end{array}$ \\
\hline 1 & Австралия & 5947 & 48845 & 1,45 & 1,47 & 2,24 & 1,75 \\
\hline 2 & Великобритания & 5716 & 37334 & 1,29 & 1,41 & 2,10 & 1,72 \\
\hline 3 & САЩ & 3736 & 53015 & 1,83 & 1,91 & 2,24 & 1,63 \\
\hline 4 & Германия & 3715 & 44689 & 1,72 & 2,00 & 4,40 & 1,26 \\
\hline 5 & Италия & 3143 & 33419 & 1,63 & 1,88 & 4,51 & 0,89 \\
\hline 6 & Франция & 3086 & 37124 & 1,72 & 1,69 & 3,55 & 1,19 \\
\hline 7 & Канада & 2866 & 43745 & 1,88 & 1,45 & 2,69 & 1,31 \\
\hline
\end{tabular}

Източник: Изчисленията са на автора по данни от Maddison Project Database

Поради това следващата стьпка в анализа е определяне на най-динамичните периоди в развитието на горните пет азиатски страни в рамките на изследвания период. Те постигат своя успех в различно време, но най-вече след Втората световна война. Затова акцентът е върху периода 1950-2016 г., който е най-динамичният период за последните 150 години и от своя страна може да се подраздели на два подпериода: 1950 -1980 г. и 1980-2016 г. Темповете на нарастване на БВП на човек за целия период и по подпериоди са представени в таблица 3.

Таблица 3. Средногодишни темпове по подпериоди на най-динамичните пет страни

\begin{tabular}{|l|l|l|l|l|}
\hline Страни & \multicolumn{4}{|l|}{ Средногодишен темп } \\
\hline & $\begin{array}{l}\text { 1870- } \\
\mathbf{2 0 1 6}\end{array}$ & $\begin{array}{l}\mathbf{1 9 5 0 -} \\
\mathbf{2 0 1 6}\end{array}$ & $\begin{array}{l}\mathbf{1 9 5 0 -} \\
\mathbf{1 9 8 0}\end{array}$ & $\begin{array}{l}\mathbf{1 9 8 0}- \\
\mathbf{2 0 1 6}\end{array}$ \\
\hline Корея & 3,02 & 3,97 & 5,38 & 5,27 \\
\hline Тайван & 2,67 & 5,35 & 6,00 & 4,80 \\
\hline Хонг Конг & 2,64 & 3,04 & 4,89 & 3,40 \\
\hline Сингапур & 2,5 & 4,15 & 4,56 & 3,80 \\
\hline Япония & 2,41 & 2,90 & 6,70 & 1,60 \\
\hline
\end{tabular}

Източник: Изчисленията са на автора по данни от Maddison Project Database

Периодът 1950-1980 г. се оказва най-успешният и за петте страни. През този период най-високи темпове на нарастване на БВП на човек е постигнала Япония от 6,7\%, Тайван $6 \%$, Република Корея - 5,38\%. Корея запазва тези високи темпове и през следващия период, докато Япония изпада в стагнация и има темпове под $2 \%$. Таблица 3 показва, че по-високите дългосрочни темпове за 150 годишния период са са резултат преди всичко на значителни успехи постигнати в след 50-те години на миналия век, а за някои страни (без Япония) продължили, макар и по-бално, и до наши дни. Големият въпрос на който се търси отговор е как този растеж, наречен от много изследоветили „икономическо чудо” е станал възможен.

\section{2. Теоретични и емпирични изследвания за ускореното развитие}

Икономическите успехи на Япония и четирите страни от Източна Азия са обект на теоретични и емпирични изследвания през 90-те години (виж например: Yeh, 1991; Petri, 1993; World Bank, 1993; Page, 1994; Collins et all, 1996; Leipziger et all, 1993) и продължават и до днес (виж Seliger 2010, Virmani 2012, Popov 2015). Част от публикациите насочват 
вниманието към групата страни като цяло на основата на сравнителен анализ, докато други изследват отделно взета страна (виж Li, 2005; Aganbegov et all, 2016)

В основата на тези изследвания стои стремежът на авторите да откроят онези доминиращи фактори, които са характерни за всички страни осъществили „икономическо чудо“. Целта е очевидна - ако се откроят общите закономерности, водещи до ускорена икономическа динамика, то те могат да се използват като градивен елемент на модели и за други страни, които изостават в своето развитие.

Прегледът на литературата по този въпрос показва, че голяма част от тях стигат до извода, че съществува голямо разнообразие в началните условия, в провежданите политики, а и във времето на осъществяване и поради това един единствен фактор не може да даде обяснение за радикалния икономически скок.

В изследване за част от петте страни, които сме посочили като най-динамични, а именно Корея, Тайван и Хонг Конг, К. Йе (Yeh, 1991) посочва, че сред най-важните характеристики на успешния им икономически модел е експортната им ориентация - “Един стилизиран модел на тяхното развитие би трябвало да очертае техните политики като ориентирани навън, движени от пазара, насърчаване на износа и основани на вътрешна икономическа либерализация" (Yeh, 1991, p.10). По-конкретно, Йе обобщава характеристиките на успешния азиатски модел в следните четири пункта:

1. Стратегия за развитие, ориентирана към износа;

2. Движеният от износа растеж се основава в началото на продукти на трудовоинтензивни производства, изискваща индустриализация;

3. Висока норма на инвестиции;

4. Ролята на държавата е различна, но общото е малко правителство с фокус върху инфраструктурата и създаване на условия за ефективна предприемаческа дейност.

Едно от най-обширните изследвания, посветено на успеха на тези страни е на Световната банка (The world bank, 1993). Основният извод от проучването е, че не може да се открои един единствен модел, който да се използва като рецепта за ускорен растеж. И все пак се констатира, че три основни фактора, които икономистите традиционно свързват с икономическите растеж, различават тези пет азиатски страни, от другите развиващи се икономики.

На първо място, това е висока норма на инвестиции, като дял от БВП. В периода между 1960 и 1990 те надвишават 20\% от БВП. На второ място, това са инвестициите в човешки капитал. Изразяват се основно в универсалното начално и средно образование, което води до изключително квалифицирана работна сила. Третият фактор е растежът на производителността на труда.

Първите два фактора, според това изследване, осигуряват приблизително две трети от темпа на растежа, а остатъкът е от общата факторна производителност (ОФП). Констатира се, че ръстьт на производителността на труда превишава значително този на повечето други развиващи се и индустриални икономики. Причината за това се търси във високата ефективност при насочването на спестяванията към високодоходоносни инвестиции и ускореното в резултат на това технологично догонване на развитите индустриални икономики.

Ролята на общата факторна производителност, като определяща за растежа, не се споделя обаче от всички автори. Противоположно мнение се защитава от Колинз и Босуорт (Collins et all, 1996) в проведено от тях иконометрично изследване за страните от Източна Азия. Те стигат до извода, че за огромния растеж на тези икономики, ролята на ОФП се надценява, а тази на натрупването на физически капитал значително е подценена. Тяхната оценка е, че в региона ОФП расте с $1,1 \%$ на година, което е на нивото на другите индустриални страни по това време (без САЩ). Приносът на ОФП в региона за нарастването

\footnotetext{
5 Това е книгата на Ли Куан Ю за възхода на Сингапур, която е автобиографична.
} 
на БВП на човек за трийсетгодишния период след 1960 г. е около една четвърт. За Колинз и Босуорт икономиките в Източна Азия се различават от другите страни предимно по отношение на натрупването на капитал, а не на растежа на ОФП: „Поуки от високия азиатски растеж трябва да се търсят във величината и постоянството на натрупването на капитал, а не от изгодите, носени от производителността" и понататьк "И по специално, драматичните увеличения на спестяванията са отличителен белег за успешното им развитие“ Collins et all, 1996, р.173, 175). С други думи, те твърдят че, източноазиатските страни се справят толкова добре, защото са готови да направят жертвите, необходими за натрупване на капитал с много високи темпове.

Според Дж. Пейдж (Page, J. 1994) съществуват няколко възгледа за радикалния икономически скок и успех на тези страни. Първият възглед, наречен традиционен, приема за доминираща роля натрупването на фактори на производство и тяхното ефективно разпределение. Втората група икономисти, признавайки ролята на факторното натрупване, акцентира върху успешното технологично догонване на тези страни с най-развитите. Емпирично този извод те подкрепят чрез доказване на растежа на общата факторна производителност. Третият възглед е на изследователи, които виждат най-важната предпоставка за ускорения растеж в първоночалните условия в тези страни - високо образование и относително равенство в доходите.

Обобщавайки литературата, изследваща източноазиатския успех, П. Петри (Petri, 1993) посочва три възможни теории. Първата се основава на неокласическата теория и акцентира върху: а) търговска стратегия, насочена към засилен износ и световните пазари. Тук обаче има разнообразие на политики, вариращи от протекционизъм (Япония и Корея) до пълна либерализация (Хонг Конг); б) провеждане на консервативна макроикономическа политика за да има стабилна и предсказуема за спестявания и инвестициите макросреда. Поддържане на ниска и стабилна инфлация и нисък държавен дълг; и в) поддържане на конкуренти пазари за осигуряване на структурна трансформация от аграна икономика към индустриална икономика. Втората теория, спадаща към структуралистките теории, търси обяснението в провежданата успешна индустриална политика и необходимостта от силно лидерство на държавно равнище. Привържениците на тази теория за ускорения растеж смятат, че провежданите в тези страни политики значително се отклоняват от политиките на свободния пазар. Според този възглед, държавните целенасочени интервенции са в основата на успеха. Без тях не би могъл да се укрепи даден прохождащ отрасъл и да се създане новата, индустриална структура на икономиката. Третата теория застъпва културалисткия подход и търси корените на успеха в характерните особености и традиции на тези общества, силно повлияни от конфуцианството. Това оказва силно влияние върху икономическото поведение, социалната организация и методите на управление. Някои от проявите на конфуцианските традиции могат да се търсят в склонноста към спестяване, стремежа към образование, приоритет на общностните пред индивидуалните ценности, създаване на институции, осигуряващи меритократично управление, сравнително авторитарно управление, отличаващо се с дългосрочност и стабилност на политическия живот .

И трите теории акцентират върху определени аспекти, имащи отношение към икономическия растеж. Тези теории не могат да се отхвърлят, те дават известно обяснение за динамичния растеж на петте страни, но имат и своите слабости. Например, неокласическите фактори обясняват в известна степен успеха в тези страни, но не могат да обосноват именно експлозивния скок в определени периоди от време. Структуралистките теории не се потвърждават изцяло емпирично, защото само Япония и Корея (в някаква степен и Тайван) в голяма степен използват силна държавна интервенция, докато Хонконг прилага принципите на свободния пазар, а при Сингапур се наблюдава по-скоро следване на прагматична политика. Аргументите на културалистката традиция също не трябва да се приемат за определящи, защото културните норми са относително консервативни във времето и са от хилядолетия, а онова, което се наблюдава в тези страни е драматична промяна на 
икономическото поведение на икономическите агенти в сравнително кратки периода от време.

Амбициозен опит да разработи теория за „икономическите чудеса“ прави Б. Селиджър (Seliger, 2010). На основата на сравнителен анализ между Германия, чието икономическо чудо започва през 50-те и Япония плюс четирите страни от Източна Азия той посочва някои от съществените различия в икономическите модели на тези страни. Германия залага на конкуренцията и малки и средни предприятия ${ }^{6}$, докато Япония и Корея използват като двигател големите стопански конгломерати (дзайбацу и чебол), подкрепяни от правителствата и осъществяващи дейността си на основата на определени привилегии. Освен това Германия се развива в условията на интеграционна европейска общност (Европейската общност за въглища и стомана е създадена през 1951 г.) докато дълги години азиатските страни следват тьрговска политика, която остава на страна от интеграционни общности ${ }^{7}$ Независимо от тези, а и други различия, Б. Селинджър смята, че сьществува и нещо общо и то е в икономическите институции. Става дума преди всичко за онова съчетание на формални и неформални институции и в двете групи страни, което формира стабилна институционална среда и е основа за икономически модел, който позволява дългосрочно разработване на национални политики и планове на частните фирми. С други думи, общото не е в конкретните институционални форми, а в техните функции. Преди всичко в това, че изградените икономически институции създават условия за дългосрочното натрупване на частни инвестиции и човешки капитал.

Значението на институциите за растежа се споделя и от други автори. Например подчертавайки многообразието от условия и политики, довели до ускорения растеж и отсъствието на единствена формула Липзингер (Leipziger et all, 1993) посочва три групи фактори: първоначални условия и дадености, провежданите политики и накрая, развитие на институциите.

\section{3. Дискусия за факторите за ускорено развитие и поуки за България}

Целта на статията е търсене на възможности за ускоряване на икономическото развитие на България на основата на изследване на причините, довели до качествен скок в най-динамичните в икономическо отношение страни. Възниква закономерният въпрос: Могат ли тези невероятни икономически успехи, признати и наречени от изследователите „източноазиатски икономически чудеса“ да се възпроизведат в други страни, в т.ч. и в България? Отговорът зависи от това как изследователят вижда причината за източноазиатския успех.

Онези, които виждат причината за успеха на Източна Азия в специфичните политики, насочени към външните пазари и ускоряване на износа, са склонни да проявяват значителен оптимизъм по отношение на възможността за изграждане на подобен модел. Подобен оптимизъм би породил и модел, основан на акумулирането на физически и човешки капитал. Ако се застъпва позицията, че уникалността на азиатския успех се корени в по-дълбокия културен и народопсихологически компонент на средата, както и на съответните институции, то би надделял песимизмът.

Смятаме, че нито прекаленият песимизъм и обреченост, нито прекаленият оптимизъм, че догонването е лесно осъществимо имат място в сериозните икономически анализи. Установено е, че има страни, които са осъществили качествен скок в развитието си ${ }^{8}$. Доказано е, че ускореното развитие може да се осьществи при различни стратегии-с по-

\footnotetext{
${ }^{6}$ В това отношение Тайван прилича на Германия.

${ }^{7}$ Изключение е Сингапур, членуваща в АСЕАН от 1967 г.

${ }^{8}$ В тази статия сме се ограничили до първите пет страни в направената от нас ранклиста за темповете на растеж на реалния БВП на човек. Извън обсега на изследване остават Финландия, Норвегия и Швеция (заемащи съответно 7, 8 и 9 място), както и Малазия, Тайланд, Китай и Ирландия (съответно на 11,12,13,14 място.
} 
малко или по-голямо участие на държавата. Истинският проблем е не разработването, а осъществяването на политики, които да съответстват на времето и да са правилно насочени и структурирани. Те трябва да отговарят на основните изисквания за икономически растеж и не само да отразяват, но и да развиват институционалния капацитет на съответната страна. Необходимо е не следването на идеологически и теоретични конструкции, а провеждането на прагматични политики. Едно от пьрвите неща, с които е започнал през 1965 г. Ли Куан Ю, стратегьт на преобразяването на Сингапур, е озеленяването и чистотата на града и култивиране на навици за поддържане и развиване на постигнатото ( $\mathrm{Li}, 2005)$. И до днес, той е сред петте най-чисти градове на планетата.

Изследваната литература показа, виждането на повечето автори, че ускорено развитие не може да се постигне без значителен скок в натрупването на физически капитал. Малки страни не могат да постигнат ускорено развитие на основа на вътрешно потребление. Освен това, всички изследвани страни имат производство, насочено за износ. Успоредно с това е необходимо развитие на образованието, формиране на човешки капитал, при това не изобщо, а конкретно насочено в съответствие с избраните приоритетни отрасли. Не подлежи на съмнение необходимостта от ефективна държавна бюрокрация, съставена от технократи и институции, гарантиращи нулева толерантност към корупцията. Независимо от противоположните мнения, водещата роля на държавата при осъществяването на целенасочени политики смятаме за задължителна. И не на последно място са нужни лидери с ясна визия за бъдещето на страната, с воля за осъществане на възприетите политики, както и народ, обединен около предлаганите мерки и промени, който е съгласен да бъде воден в съответната посока, защото е разбрал, че участва в разпределението на плодовете от постигнатия растеж.

\section{Заключение}

Основните изводи могат да се обобщят в няколко пункта.

1. Ускореното развитие и догонване в рамките на едно поколение е възможно и то може да се случи в различни страни.

2. В петте изследвани страни има значително разнообразие на следвани икономически модели. Не може да се открои един единствен модел, гарантиращ ускорено развитие.

3. Стратегията за развитие на дадена страна, желаеща ускорено развитие, не е резултат на късмет, а на търсене, подходящи реформи, експериментиране и прагматичност, а не следване на идеологии. Необходим е уникален модел, а не имитиране.

4. Независимо от необходимостта на уникална стратегия за догонващо развитие, онези най-общи условия, без което нито една стратегия не може да мине са:

- инвестиране в човешки капитал и развитие на образование, но специфично насочено.

- инвестиции в капитал, ефективно насочвани в дейности, които са приоритетни;

- експортно ориентирана икономика (в днешно време ефективно интегрирана в икономическа общност)

- ефективна, добре платена и некорумпирана държавна бюрокрация, работеща за обществото;

- силни и образовани лидери с визия за желаното състояние на страната и икномиката

- споделяне на резултатите от растежа от мнозинството, а не концентрация на богатство;

- институции, които да съдействат и създават стимули за горните шест условия.

\section{References}

1. Aganbegov, S.I. and E.A. Levin. (2016). Yaponiya- chudo economicheskogo rosta i chudo stagnatsii. Eko. №11.

2. Collins, S. M. and B. Bosworth. (1996) Economic Growth in East Asia: Accumulation versus 
Assimilation. Brookings Papers on Economic Activity, 2. [Online] Available from: https://www.brookings.edu/wpcontent/uploads/1997/06/1996b_bpea_collins_bosworth_rodrik.p df [Accessed 09/10/2019].

3. The world bank (1993). The East Asian Miracle: Economic Growth and Public Policy. Oxford University Pres. [Online] Available at http://documents.worldbank.org/curated/en/ 975081468244550798/pdf/multi-page.pdf. [Accessed 5/10/2019].

4. Leipziger, Danny M.; Thomas, Vinod. 1993. The lessons of East Asia : an overview of country experience. Washington, DC: The World Bank. [Online] Available at: http://documents.worldbank.org/curated/en/958161468770740374/The-lessons-of-East-Asia-anoverview-of-country-experience. [Accessed 1/10/2019].

5. Li, K.Yu. (2005). Singaputskaya istoriya. Iz «tretyevo mira» - v pervay». MGMIO, MID Rossii, M.

6. Maddison Project Database, version 2018. Bolt, Jutta, Robert Inklaar, Herman de Jong and Jan Luiten van Zanden (2018), "Rebasing 'Maddison': new income comparisons and the shape of long-run economic development [Online] Available from https://www.rug.nl/ggdc/ historicaldevelopment/maddison/releases/maddison-project-database-2018 [Accessed 1/08/2019].

7. Page, J. (1994) The East Asian Miracle: Four Lessons for Development Policy. in: NBER Macroeconomics Annual 1994, Volume 9. MIT Press, pp. 219 - 282. [Online] Available from: http://www.nber.org/books/fisc94-1. [Accessed 5/10/2019].

8. Petri, P. A. (1993) The Lessons of eEst Asia, Common Foundations of East Asian Success, The World Bank.

9. Popov, V. (2015) Catching Up: Developing Countries in Pursuit of Growth, MPRA Paper No. 65878.[Online] Available at https://mpra.ub.unimuenchen.de/65878/1/MPRA_paper_65878.pdf. [Accessed 1/10/2019].

10. Seliger, B. (2010) Theories of economic miracles, Ordnungspolitische Diskurse, No. 2010-01. [Online] Available at: http://hdl.handle.net/10419/55426. [Accessed 1/11/2019].

11. Virmani, A. (2012) Accelerating And Sustaining Growth: Economic and Political Lessons. International Monetary Fund, WP/12/185. [Online] Available from: https://www.imf.org/external/pubs/ft/wp/2012/wp12185.pdf [Accessed 12/10/2019].

12. Yeh, K. C. (1991) The Lessons of East Asian Development and Alternative Development Strategies for Hainan, RAND. [Online] Available at https://pdfs.semanticscholar.org/ cc8a/1cd30b1f546bed63bc58da48d1837b79c543.pdf. [Accessed 5/10/2019]. 